\title{
Effectiveness of Reading Aloud Strategies for Inferential Reading Comprehension Skills and Text Difficulties of Saudi Students at University Level
}

\author{
Muhammad Khalid Mehmood Sajid, Abdullah Al Fraidan
}

\begin{abstract}
Reading comprehension is the ability to process text. It is an essential part of learning for university students. A lot of strategies are used for reading. Among them, reading aloud strategies are vital reading strategies. Saudi Arabia is a country where English is to be spoken as a second language. Due to weak school basal reading, the Saudi students have problem with reading text level where they are failed at university learning material for high-level reading skills such as inferential, evaluative, and critical reading. However; in this study, a survey was distributed among 27 students to know their opinion about the effectiveness of reading aloud strategies for inferential reading comprehension skills and text difficulties of Saudi students at the university level. Convenience sampling was used as both the researchers were from the same place. The study was conducted at the Department of English. College of Arts, King Faisal University, Alhasa. SPSS descriptive statistics were used for analysis by using SPSS version 21. Atlas-ti 8 reports were also used for the elaboration of major themes during the literature review from previous research studies. The findings showed reasonable effectiveness of these strategies. These strategies were also recommended for future research on inferential reading comprehension skills and the solution of difficult text by having the present set up of strategies being used by Saudi university level students.
\end{abstract}

Keywords: Read aloud strategies, reading comprehension, inferential reading skills, text difficulties

\section{INTRODUCTION}

In the past several decades, reading has played an important role in students' learning process. As an important task, reading has a prominent place in the learning process. Recent theoretical developments have revealed that reading is a very important skill. A lot of great reading studies adopted it as a significant target. A critical area of English language teaching is the use of the best reading skills (Hamouda \& Development, 2013). These reading skills are very important for any text reading material (Berardo, 2006). There are three types of reading skills: literal, inferential, and evaluative. Saudi students' university learning material is often written from inferential to evaluative level skills which are produced by highly elevated style writers of Europe, Canada, or the USA.

Revised Manuscript Received on October 15, 2019.

Muhammad Khalid Mehmood Sajid, PhD Scholar at Centre for Modern Languages \& Human Sciences, Universiti Malaysia Pahang, Malaysia, English Language Lecturer, College of Applied Medical Sciences, King Saud Bin Abdul Aziz University for Health Sciences, Alhasa, Saudi Arabia(Email: interstudies2000@gmail.com)

Abdullah Al Fraidan, Associate Professor, English Language Department, College of Arts, King Faisal University, Alhasa, Saudi Arabia(Email: afridan@kfu.edu.sa)
On the other hand, according to Al-Nujaidi (2003), the reading abilities of most of the Saudi students fall under the category of basic reading skills as they enter the university colleges from school level where Saudi teachers in Second Language are teaching them, and this L2 becomes a severe problem for them at University level (Crystal, 2012). Here, as a result, the students become stuck not only in reading but all the required English language skills. University teachers often use different strategies as provided in teachers' edition as a guide for solving their problems. First, they try to solve their text difficulty problems and then the required reading skills. Among different reading strategies, reading aloud strategies are used very less as the (Alsamadani, 2008). However; many researchers have repeatedly pointed out the importance of RAS at the university level for the solution of students' problems (Brantmeier, 2002; Lane \& Wright, 2007). Some consider RAS as one of the vital reading strategies at this level for text level difficulties and highlevel readings skills required by Saudi students (Gibson, 2008; Ness, 2016).

Freshly, a significant literature has grown up around the theme of reading comprehension for inferential reading skills of Saudi students. These new growths in the field of these reading skills have led to a new interest in inferential reading comprehension for reading text level difficulties of low proficient Saudi reader students. Furthermore, it is still not identified whether Saudi university students have right inferential reading talent by using reading aloud strategies at the university level. Now, there is no information on it. Very less is presently acknowledged about it. What is not yet clear is the influence of reading aloud strategies on these undiscovered variables. This designates a need to comprehend the various sensitivities of this issue that exist among the above-said variables. It is now well-known that reading aloud strategies toil at school level pupils very well. Nevertheless, the effect of reading aloud strategies on university students for inferential reading skills and text difficulties has kept on uncertain.

\section{BACKGROUND}

\section{Review of Literature:}

In this part, the assessment of numerous studies will be discussed grounded on the effectiveness of reading aloud strategies for inferential reading comprehension skills and text difficulties of Saudi students at the university level. 
The English language has four main and two subsidiary skills. The main skills are listening, reading, writing, and speaking, but the subsidiary skills are accent and grammar. Reading is the most crucial language skill because it is the base of knowledge (Birch, 2014). This skill has a vital meaning on humans; that is why it is the crucial reason for learning and proficiency. Alshehri (2014) has called it a distinctive procedure which rounds through eyes, speech, and mind. The main purpose of teaching the reading skill to train the students so that they could attain info to comprehend what has been recited. Further, his studies of research thesis show the importance of reading comprehension as an ability for reading the text and understanding the ideas of the author. It uses prior information, constructing guesses and sketching out respected evidence among other issues.

It has previously been observed that reading teachers use different reading strategies for improvement in reading comprehension among students. Among them, silent reading strategies and reading aloud strategies are famous reading strategies. Research studies such as that conducted by (Bolos, 2012) has shown that simple strategies should be given preferences that enable hold of reading skills. He further wrote that these strategies should be implemented in a classroom for the whole educational tenure of a student. It is an automatic strategy which appears with hard text having a loud setting. Addition of this strategy will have a positive effect on the students' vocabulary. (Kaliyadan et al., 2015). It is a planned oral reading of a text connected to the topic of a study. It is an essential reading strategy as it raises the basic skills and understanding. Up to now, several studies confirmed the effectiveness of RAS on text difficulties(Eason, Goldberg, Young, Geist, \& Cutting, 2012). One study by Bolos (2012) examined the trend in literacy development through these strategies. Al-Mansour and Al-Shorman (2011) have reported that these strategies have been being used from over seventy-five years, which validate their significance for students. The study by (Andersson \& Barnitz, 1984) proposals perhaps the most inclusive pragmatic investigation of RAS who have defined Ras as the single most important action for structuring the familiarity required for ultimate achievement in reading is reading aloud to the needy students.

It is now well established from a variety of studies that there are different levels of reading comprehension skills (Morgan \& Fuchs, 2007). The first basic level starts from literal reading comprehension skill, which is the fundamental reading skill. The second level of reading skill is an inferential reading skill, and the last level is evaluating skills. However; most of the previous studies have argued that inferential reading skills are necessary for a college student. There are several reasons: First, to identify the main idea, supporting details, to make assumptions, to draw conclusions, and to make a good inference. Second, these strategies develop confidence among weak proficient students. Third, students improve personal knowledge to construct meaning beyond what is literally stated and to make inferences in the sequence, cause, and effect relationships. They help students to understand the title, theme, and purpose of a passage. In one of the research, Trelease (2013) has found them making students easy for finding out a topic sentence and to understand the tone of the passage with deeper meaning of the text. Students become able to deduce gist from what was read to help grasp text and to subtract and read between the lines.

To sum up, inferential reading comprehension skills are necessary to learn by university students for complex text. However; the last reading comprehension skill is an evaluative skill which is used by high-level graduates, e.g. Ph.D., MPhil, or Post-doctoral students. As the current study fixed its focus around Saudi university students, hence, the concern here is inferential reading comprehension skills. It has conclusively been shown that Teo, Jen, and Technology (2012) have found these strategies provide the reader brings theoretical familiarity, common sense, inferential skills, and information of text erection to reading. The reader cartels these acquaintance bases with text plans to formulate a text classically (Walczyk, Marsiglia, Bryan, \& Naquin, 2001).

Kispal (2008) points out a key finding in his review that RAS can provide magnet inferences from a text. This has been discussed by a great number of authors in literature. Alshehri (2014) claims that there is an increase in understanding of the texts when reading aloud is used. These strategies also provide opportunities for readers to increase their comprehension skills. He further maintains that the reading aloud plans are positive for them in evolving an understanding of the text for evocative upshots. Johnston (2015) confirms the importance of these strategies for intricated text. These enable students' levels better from early levels to even after graduating high school. Then, students understand logical inferences while reading difficulty text easily. When using them continually for a long time, after perfection with text complexity and inferencing skills, these strategies start developing the critical thinking skills of these capable students. He further expanded his experience and said that not only for academic text but many diverse kinds of text can be effective for practice of these strategies. While writing about the findings of his research study, he argued that RAS during questions and discussions about "what, when, where, why," assisted knowledge, and also his open-ended questions were showing to permit students the capability to style inferences grounded on the text and prolonged their inferential reading comprehension skills. Because these strategies encourage students understanding and refer to the text so that they could predict, they increase inward conversation with the text autonomously. Successful activities of these strategies are highly beneficial. College students need to read difficult text where they need inferential reading skills. RAS increase their text repetition and paraphrasing abilities, and, they become capable of generating inferences which require them to have time to complete.

There are predictions that these strategies work for university student very well not only for inferencing skills but also, they grasp evaluating skills. The students can answer the question from the complex text easily for identified consequences and fix their focus for inferencing 
with more attention (Van den Broek, Lorch, Linderholm, Gustafson, \& Cognition, 2001). A series of recent studies have indicated that low proficient readers are less likely than good readers for inferential reading comprehension skills while interacting with the difficult text. Gap satisfying inferencing for the complex text is highly required for university-level students. RAS makes relations amid diverse parts of a text, coding for the data, the interval of interference, the amalgamation of their familiarity with the hard text for producing inferential reading comprehension skills (Hall, 2016). Overall, these studies highlight the need for a turn out to be a good reader at the university level. A student needs to understand the problematic text of his learning material which is linked with improved comprehension consequences and RAS make them able to improve their text comprehension to bring them to a certain level that they could have acquaintance how to become good at inferential reading skills. Considering all this evidence, it seems that these strategies are very effective not only for difficult text but also for inferential reading comprehension abilities of university students.

\section{MATERIAL AND METHODS}

The present study was based on the effectiveness of reading aloud strategies for inferential reading comprehension skills and text difficulties of Saudi students at the university level. It was survey research. The study was conducted in a Saudi university (King Faisal University). The location was the College of Arts, English Department, Alhasa city, and the data was collected from the English department. Data was collected with the help of a survey questionnaire. A sample size of 27 students was taken, including all male students. As both the researchers were having teaching job assignments in the same city which were King Faisal and King Saud Bin Abdul Aziz University for Health Sciences, Alhasa, Saudi Arabia, so sampling was done on convenience based. All the available participants were taken as a convenience sampling. No student was absent, and all the participant took part in the survey questionnaire for answering the items. Convenience sampling is economical and saves the precious time of the researchers for fruitful, positive, and quick results. It is the supreme effective sampling for a survey research inquiries (Hartati, 2017).

\section{FINDINGS}

\section{Students' Questionnaire response:}

In table 1, it can be observed that results from the first question on the effectiveness of RAS for students' inferential reading skills everybody ticked that it was effective. All of them were satisfied that these strategies helped them for inferential reading comprehension skills.

Table 1

Reduce text level difficulties for positive effects on students' inferential reading comprehension skills

\begin{tabular}{|ccc|}
\hline & Frequency & Valid Percent \\
\hline Effective & 27 & 100.0 \\
\hline
\end{tabular}

In table 2, the results were obtained using SPSS. Results show that not only survey research showed read aloud as a better strategy but also the questionnaires obtained results were better for a read-aloud strategy for helping them to determine the deeper meanings from the text. All of them agreed that they have a full approach by using these strategies to assess the deeper meanings of the material learning texts.

Table 2

Help me to determine the deeper meanings from the texts

\begin{tabular}{|ccc|}
\hline & Frequency & Valid Percent \\
\hline Effective & 27 & 100.0 \\
\hline
\end{tabular}

According to students' response as shown in Table 3, the percentage value of Q.3 Help me to infer meaning from what was read to help comprehend text was 5 and 6 for effective and somewhat ineffective but it was 7 and 9 for neutral and effective. The number of respondents who strongly agreed with the statement that read aloud strategy was helping them to infer meaning from what was read to help comprehend text was $33.3 \%$, while $38.8 \%$ respondents agreed, $25.9 \%$ were neutral, $18.5 \%$ disagreed while $22.2 \%$ thought that was somewhat ineffective.

Table 3

Help me to infer meaning from what was read to help comprehend text

\begin{tabular}{|ccc|}
\hline & Frequency & Valid Percent \\
\hline ineffective & 5 & 18.5 \\
somewhat & 6 & 22.2 \\
ineffective & & 25.9 \\
Neutral & 7 & 33.3 \\
Effective & 9 & 100.0 \\
Total & 27 & \\
\hline
\end{tabular}

Table 4 demonstrates the percentages for Q.4, help me to deduct and read between the lines of a difficult text of the reading passage, was $11.1 \%$ for ineffective. Collected information shows that $22.2 \%$ of respondents strongly agreed that RAS was somewhat ineffective, $22.2 \%$ respondents were neutral, $18.5 \%$ of respondents had a perception that these were somewhat effective, and $25.9 \%$ of respondents thought that these strategies were effective.

Table 4

Help me to deduct and read between the lines of a difficult text of the reading passage $(n=27)$

\begin{tabular}{|ccc|}
\hline & Frequency & $\begin{array}{c}\text { Valid } \\
\text { Percent }\end{array}$ \\
\hline ineffective & 3 & 11.1 \\
somewhat & 6 & 22.2 \\
ineffective & 6 & 22.2 \\
Neutral & 5 & 18.5 \\
Somewhat & 5 & 25.9 \\
effective & 7 & 100.0 \\
Effective & 27 & \\
Total & &
\end{tabular}




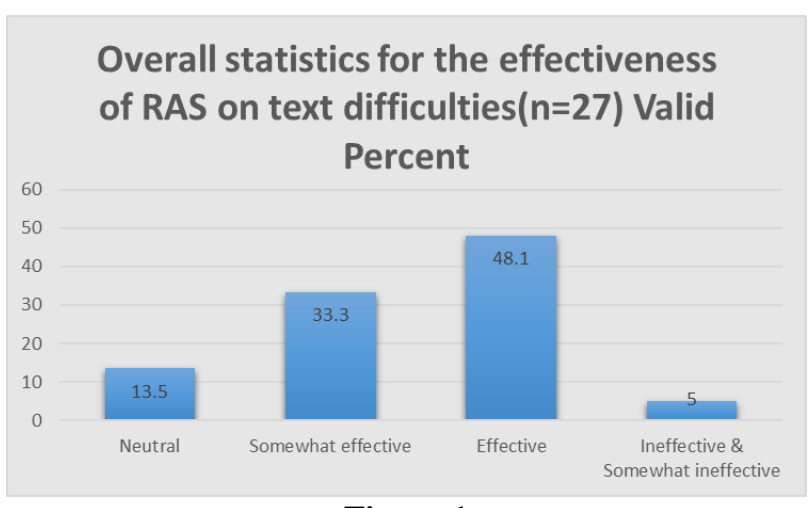

Figure 1

Statistics on the overall performance of RAS for the effectiveness of RAS on text difficulties
The figure 1 shows detailed statistics on the overall performance of RAS for research Q.1, the effectiveness of RAS on text difficulties, five students were neutral, and the percentage was 18.5. Collected information shows that $33.3 \%$ of respondents agreed that read aloud strategy was somewhat effective is helpful in the transition, $48.1 \%$ respondents strongly agreed that these strategies were effective, while $5 \%$ response was found for ineffective and somewhat ineffective. The results clearly show that RAS were effective for improving students' text comprehension abilities at university level text, and they did not have text difficulty.

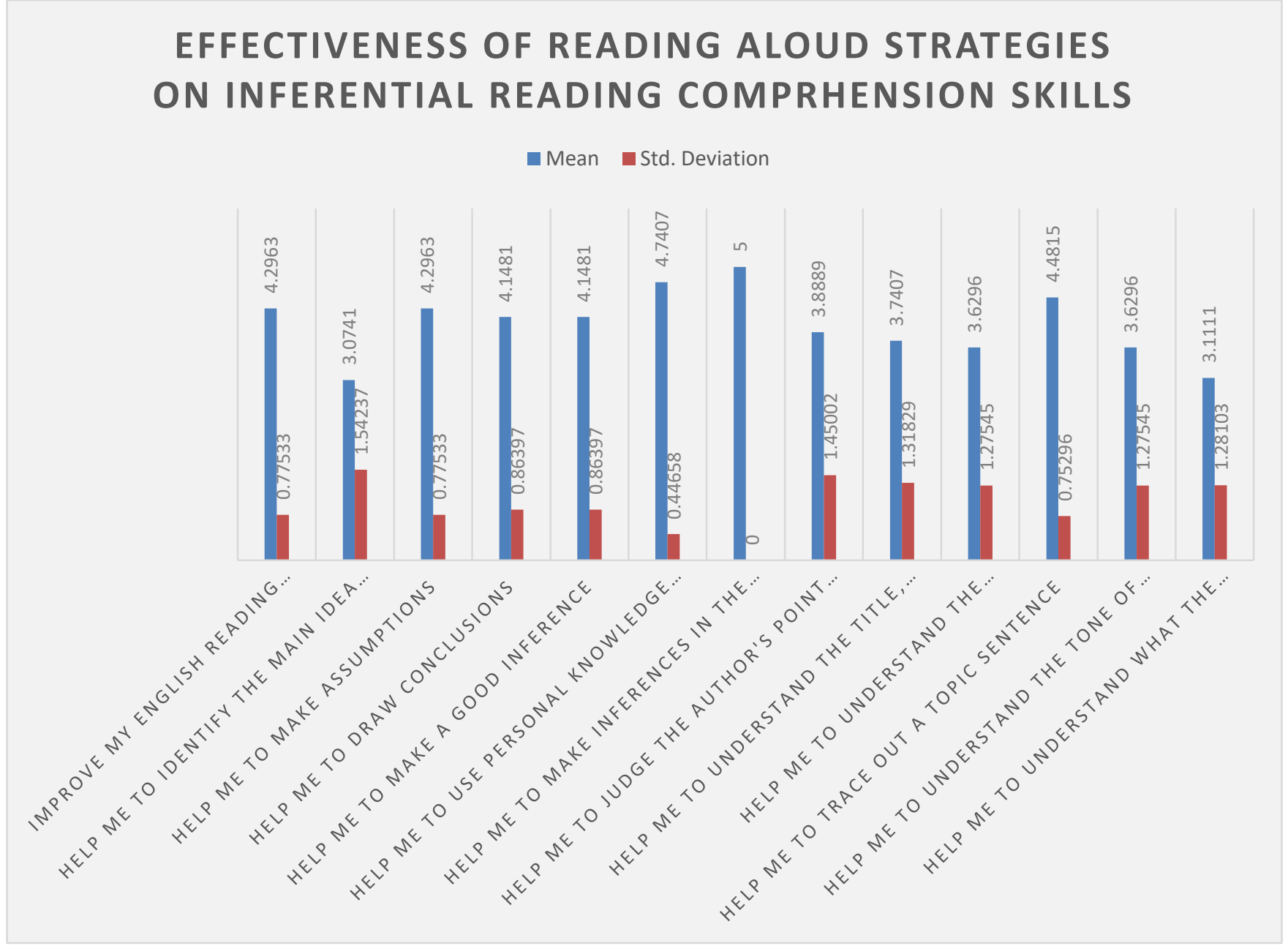

Figure 2

Statistics for the effectiveness of RAS on inferential reading comprehension skills(n=27)

The detail description for Figure 2 shows that the mean value for Q.1, improve my English reading inferential skills, was 4.2. According to provided response, the SD was 0.77; respondents strongly agreed that whatever teachers read aloud they can easily understand. The mean value for Q.2, help me to identify the main idea and supporting details, was 3.0, and the SD was 1.5. As regards, question No.3, help me to make assumptions, the SD was 0.77 , but the mean score was 4.1. However, responses for question 4 and 5, help me to draw conclusions-help me to make a good inference, were the same as the mean score was 4.1, and the SD was 0.86. Mean score and SD were 4.7, 5.0 and $0.44,0.0$ positively for question $6 \& 7$, help me to use personal knowledge to construct meaning beyond what is 
literally stated- help me to make inferences in the sequence, cause and effect relationships and interpreting figurative language. Question No.: Help me to judge the author's point of view, had an SD of 1.4 , while the mean score was 3.8. On the other hand, Q. 9, help me to understand the title, theme, and purpose of a passage showed mean and SD $(3.7,1.3)$. Q 10 and 11 , help me to understand the vocabulary questions in a passage- help me to understand the tone of the passage had an equal mean score of 3.6 and the same SD which was 1.2. Further, Q 11 and 13, help me to trace out a topic sentence- help me to understand what the author believes showed the mean score of 4.4 and 3.1, but SD was 0.75 and 1.2. Overall. The survey results were in favor of the effectiveness of RAS.

\section{DISCUSSION \& RESULTS}

From the results of the survey instrument, it could conclude that results for answering question 1 were more significant than the second one. The obtained percentage for the first research question rather than the average mean score from the survey instrument was high. The results for the effectiveness of reading aloud strategies on text level difficulties were better with read-aloud strategy as compared to its effects on inferential reading comprehension skills. The study was conducted for the Department of English from the College of Arts, King Faisal University, Alhasa, Saudi Arabia. Selected sample was based on university level Saudi students. Students were provided with a questionnaire having asked some questions, and obtained results were in favor of read-aloud strategies. It was observed that reading could improve read-aloud strategies; also, it helped the students understand the hard text for inferential reading comprehension. They helped the students to identify the main idea, supporting details, to make assumptions, to draw conclusions, and to make a good inference. Read aloud strategy helps develop confidence, especially in poor readers who feel shy about reading the text in front of people. With read-aloud strategies, a reader can improve to use personal knowledge to construct meaning beyond what is literally stated, and to make inferences in the sequence, cause and effect relationships and interpreting figurative language. It was helpful to judge the author's point of view, and it was also helping students to understand the title, theme, and purpose of a passage. With read-aloud strategy, students easily traced out a topic sentence, and they were able to understand the tone of the passage. Read aloud strategies made them able to understand what the author believes. These strategies not only reduced text level difficulties for positive effects on students' inferential reading comprehension skills, but they also worked for deeper meanings from the texts. Students' responses show that RAS help them to infer meaning from what was read to help comprehend text and to deduct and read between the lines of a difficult text of the reading passages. Students preferred to read aloud even at university level programs, and they felt that for inferential reading comprehension reading, readaloud strategies were very important to reduce their text level difficulties.

\section{SUGGESTIONS}

In this survey investigation, the aim was to assess the effectiveness of reading aloud strategies for inferential reading comprehension skills and the second aim of this study was to investigate the effects for text difficulties of Saudi students at the university level. The paper has argued that RAS were vital for effectiveness. However; there is a need to include in the teacher's edition that these reading aloud expert teachers should use personal experiences on inferential reading expertise to teach Saudi students (Hansen, 1981). Read aloud strategy is important outside the classroom for those students who have poor inferential reading and not only teachers but also parents can play an important role in improving their reading skills. In the learning, process reading is very important. In Saudi Arabia, because English is being used as the medium of instructions, there is a strong need to understand and learn inferential reading efficiently.

For this reason, several research studies have defined the cognitive process in different ways (Zieffler, Garfield, Delmas, \& Reading, 2008). Saudi universities can play their fundamental and significant role in building up students' base for learning the literal reading skill so that these students should have full grasp over inferential reading skills. Teachers should opt for strategies, especially reading strategies, by considering students' ability and their performance. The findings (Pearson, 1985) are relevant to our concerns where he suggested to simply making sure that guided reading questions (asked either during or after stories) include a lot of inference questions enhances both English texts specific inferential reading comprehension skills. In general, therefore, it seems that in Saudi Arabia, the university students don't have to outclass command over writing and reading English because their national language is Arabic and these both languages are opposite, and these have no similarity. Teachers should teach students in such a way that they may be able to learn basic language skills. For suggestions on considering cross-cultural schemata when assessing reading ability creativity as a mediating variable in Inferential Reading Comprehension is necessary to facilitate mastery of this reading skill by teaching more effective and engaging through practical suggestions, and model lessons (Andersson \& Barnitz, 1984; Minskoff, 2005). Overall, this study strengthens the idea that students should provide with that type of text which is of their interest. Thus, reading must also be purposeful so that students can get advantage of it as teachers should assign any written text. The nature of inferential comprehension for each text as well as the likely difficulties students will have with the difficulty level of a text. However; among measures of text difficulty: the suggestions go for testing their predictive value for grade levels and student performance or even better to let them enter in a university after an entry test of text difficulty level (Wixson \& Valencia, 2014).

Moreover, there is a need to bring amendments to structured policies in the educational system at the university level for teaching reading. Higher level students 
are taught with read-aloud strategies, and the silent reading strategies be limited to half of the percent so that they become habitual for that type of reading and understanding. In contrast to that, the curriculum which is followed in Saudi universities level is taught by using silent reading strategies which should be half shifted to reading aloud strategies (Fareed, Ashraf, Bilal, \& Sciences, 2016; Ionkov et al., 2014, 2019; Lotfipour-Saedi, 2015).

\section{CONCLUSION}

This study has provided a deeper insight into the understanding of university-level Saudi students for difficult text and enhancement in their inferential reading comprehension skills. In Saudi Arabia, different reading strategies are being used at universities' level, but here at the College of Arts, King Faisal University, students found read-aloud strategies helpful in learning as compared to other reading strategies. Read aloud strategies are helpful to improve cognitive abilities, text structure awareness, and inferential reading comprehension skills. These strategies not only reduce text level difficulties but also work beyond literal reading skills. They not only improve inferential reading abilities but also tend to make students thinking about critical thinking. These findings contribute in several ways to our understanding of RAS and provide a basis for students to become excellent readers. The present study lays the groundwork for future research into the role of reading aloud strategies at the university level in Saudi Arabia. This study adds to the growing body of the research that indicates the role of these strategies should not be forgotten at the Saudi University level. It is also the empirical investigation into the impact of RAS on text difficulties and inferential reading comprehension skills. There is, therefore, a definite need for using teaching these strategies at Saudi universities. The challenge now is to fabricate RAS that contains other reading strategies for the university managements to enhance bumble-bee populations might involve these strategies as a key policy priority to be planned for the longterm care of weak university readers. Taken together, these findings support strong recommendations to Saudi teachers must have good expertise of reading inferential skills for difficult level university text of the suggested learning material.

\section{REFERENCES}

1. Al-Mansour, N. S., \& Al-Shorman, R. e. A. (2011). The effect of teacher's storytelling aloud on the reading comprehension of Saudi elementary stage students. Journal of King Saud University - Languages and Translation, 23(2), 69-76. doi:10.1016/j.jksult.2011.04.001

2. Al-Nujaidi, A. H. (2003). Relationship Between Vocabulary Size, Reading Strategies, and Reading Comprehension of Efl Learners in Saudi Arabia. Oklahoma State University,

3. Alsamadani, H. A. (2008). The relationship between Saudi EFL college-level students' use of reading strategies and their EFL reading comprehension. Ohio University,

4. Alshehri, M. (2014). Improving reading comprehension for Saudi Students by using the Reading Aloud Strategy.
5. Andersson, B. V., \& Barnitz, J. G. J. J. o. r. (1984) Cross-cultural schemata and reading comprehension instruction. 28(2), 102-108.

6. Berardo, S. A. J. T. r. m. (2006). The use of authentic materials in the teaching of reading. 6(2).

7. Birch, B. M. (2014). English L2 reading: Getting to the bottom: Routledge.

8. Bolos, N. J. M. S. J. (2012). Successful strategies for teaching reading to middle grades English language learners: teachers can employ a variety of classroomtested strategies to teach reading to English language learners. 44(2), 14-20.

9. Brantmeier, C. J. T. R. M. (2002). Second language reading strategy research at the secondary and university levels: Variations, disparities, and generalizability. 2(3).

10. Eason, S. H., Goldberg, L. F., Young, K. M., Geist, M. C., \& Cutting, L. E. (2012). Reader-text interactions: How differential text and question types influence cognitive skills needed for reading comprehension. Journal of educational psychology, 104(3), 515 .

11. Fareed, M., Ashraf, A., Bilal, M. J. J. o. E., \& Sciences, S. (2016). ESL learners' writing skills: Problems, factors and suggestions. 4(2), 81-92.

12. Gibson, S. J. E. j. (2008). Reading aloud: a useful learning tool? , 62(1), 29-36.

13. Hall, C. S. J. E. P. R. (2016). Inference instruction for struggling readers: A synthesis of intervention research. 28(1), 1-22.

14. Hamouda, A. J. I. J. o. A. R. i. P. E., \& Development. (2013). An investigation of listening comprehension problems encountered by Saudi students in the EL listening classroom. 2(2), 113-155.

15. Hansen, J. J. T. R. T. (1981). An inferential comprehension strategy for use with primary grade children. 34(6), 665-669.

16. Hartati, S. (2017). Self-Concept of Kindergarten Teachers about Implementation of Classroom Action Research. Paper presented at the International Conference of Early Childhood Education (ICECE 2017).

17. Ionkov, G. M., Harding, D. H., Dykstra, A. J., Grit, L. E., Petts, J. C., Minter, S. A., . . . Xi, Y. (2014). Reading material suggestions based on reading behavior. In: Google Patents.

18. Ionkov, G. M., Harding, D. H., Dykstra, A. J., Grit, L. E., Petts, J. C., Minter, S. A., . . Xi, Y. (2019). Reading material suggestions based on reading behavior. In: Google Patents.

19. Johnston, V. J. T. O. C. J. (2015). The power of the read aloud in the age of the common core. 9(1).

20. Kaliyadan, F., Thalamkandathil, N., Parupalli, S. R., Amin, T. T., Balaha, M. H., \& Ali, W. H. A. B. J. A. j. o. m. (2015). English language proficiency and academic performance: A study of a medical preparatory year program in Saudi Arabia. 5(4), 140.

21. Kispal, A. (2008). Effective Teaching of Inference Skills for Reading. Literature Review. Research Report DCSFRR031: ERIC.

22. Lane, H. B., \& Wright, T. L. J. T. R. T. (2007) Maximizing the effectiveness of reading aloud. 60(7), 668-675.

23. Lotfipour-Saedi, K. J. I. J. o. L. T. R. (2015). Suggestions toward Some Discourse-Analytic Approaches to Text Difficulty: With Special Reference to" T-Unit Configuration" in the Textual Unfolding. 3(1), 1-18.

24. Minskoff, E. (2005). Teaching Reading to Struggling Learners: ERIC. 
25. Morgan, P. L., \& Fuchs, D. J. E. c. (2007). Is there a bidirectional relationship between children's reading skills and reading motivation?, 73(2), 165-183.

26. Ness, M. K. J. R. H. (2016). Reading comprehension strategies in secondary content area classrooms: Teacher use of and attitudes towards reading comprehension instruction. 49(2), 5.

27. Pearson, P. D. J. T. R. T. (1985). Changing the face of reading comprehension instruction. 38(8), 724-738.

28. Teo, A., Jen, F. J. L. L., \& Technology. (2012). Promoting EFL students' inferential reading skills through computerized dynamic assessment. 16(3), 10-20.

29. Trelease, J. (2013). The read-aloud handbook: Penguin.

30. Van den Broek, P., Lorch, R. F., Linderholm, T., Gustafson, M. J. M., \& Cognition. (2001). The effects of readers' goals on inference generation and memory for texts. 29(8), 1081-1087.

31. Walczyk, J. J., Marsiglia, C. S., Bryan, K. S., \& Naquin, P. J. J. J. o. E. P. (2001). Overcoming inefficient reading skills. 93(4), 750.

32. Wixson, K. K., \& Valencia, S. W. J. T. R. T. (2014). CCSS-ELA suggestions and cautions for addressing text complexity. 67(6), 430-434.

33. Zieffler, A., Garfield, J., Delmas, R., \& Reading, C. J. S. E. R. J. (2008). A framework to support research on informal inferential reasoning. 7(2). 